\title{
New developments in the treatment of metastatic gastric cancer: focus on trastuzumab
}

This article was published in the following Dove Press journal:

OncoTargets and Therapy

26 March 20II

Number of times this article has been viewed

\author{
Jeffrey S Rose \\ Tanios S Bekaii-Saab \\ Department of Internal Medicine, \\ Division of Medical Oncology, \\ The Ohio State University - Arthur \\ James Cancer Hospital, Columbus, \\ $\mathrm{OH}$, USA
}

Correspondence: Jeffrey S Rose

The Ohio State University, A434 Starling Loving Hall, $320 \mathrm{~W}$. IOth Avenue,

Columbus, $\mathrm{OH} 43210$, USA

$\mathrm{Tel}+\mathrm{I}(6 / 4)$ 293-9863

$\mathrm{Fax}+\mathrm{I}(614)$ 293-4372

Email jeff.rose@osumc.edu

\begin{abstract}
Patients with metastatic gastric cancer have a poor outcome. The development of new combinations of chemotherapy has led to steady but only modest gains in overall survival with largest effects reported with two- and three-drug regimens. Trastuzumab, a fully humanized monoclonal antibody directed at the human epidermal growth factor receptor-2 (HER2), has been found to improve response rate and survival in patients with advanced gastric cancer. This update will review the role of HER2 and summarize therapeutic advances in the use of trastuzumab in advanced gastric cancer.
\end{abstract}

Keywords: gastric, gastroesophageal, adenocarcinoma, chemotherapy, trastuzumab

\section{Introduction}

In 2010, it is estimated that 21,000 men and women will be diagnosed with gastric cancer in the United States. During the same year, 10,570 will die of this disease. Worldwide, gastric cancer is the fourth most common cancer and the second most common cause of cancer death. The incidence of cardiac and gastroesophageal tumors has increased dramatically, while cancers in the distal half of the stomach have declined in the United States since the 1930s. Additionally, patient demographics have shifted with a marked increase in incidence in younger patients. With approximately $80 \%$ of patients presenting with advanced disease, palliative chemotherapy plays an essential role in the treatment of these cancers. ${ }^{1}$

Gastric cancer remains highly fatal with only modest gains in survival having been achieved with modern chemotherapy. To date, there is no standard chemotherapeutic option for patients with metastatic gastric cancer. Cisplatin and 5-fluorouracil typically combined with either a taxane $e^{2}$ or an anthracycline ${ }^{3}$ comprise the most common treatment regimens.

Targeted therapy, including inhibitors of the vascular endothelial and epidermal growth factor receptors, appears to be promising. Human epidermal growth factor receptor-2 (ErbB2 or HER2) is a well-established target that has been studied extensively in gastric cancer. Trastuzumab (Herceptin ${ }^{\circledR}$, F. Hoffman-La Roche, Basel, Switzerland), a fully humanized monoclonal antibody directed against HER2, is a standard therapy for patients with HER2 positive breast cancer, after studies demonstrated improved survival and response rates. ${ }^{4}$ This review will focus on the role of HER2 and its inhibition with trastuzumab in advanced gastric cancer. 


\section{The human epidermal growth factor receptor-2 (HER2)}

Epidermal growth factor and its receptor (EGFR or ErbB) were initially discovered in 1962 and 1978, respectively. ${ }^{5}$ The ErbB family consists of four closely related type 1 transmembrane tyrosine kinase receptors: ErbB1 (EGFR or HER1), ErbB2 (HER2), ErbB3 (HER3), and ErbB4 (HER4). Each receptor is a transmembrane protein comprising an extracellular domain at which ligand binding occurs, an alpha-helical transmembrane segment, and an intracellular protein tyrosine kinase domain. Ligand binding to these EGF family receptors phosphorylates and activates a complex intracellular signaling network, which controls a range of cellular processes including proliferation, angiogenesis, cell cycle, survival, and apoptosis. ${ }^{6}$

HER2 was the second receptor discovered in this family. Structurally, HER2 is a $185 \mathrm{kD}$ glycoprotein and a product of the c-erbB-2/neu oncogene. As opposed to the other members of the EGFR family, no ligand has been linked to HER2. Researchers believe that the receptor must homodimerize independently of a ligand, or heterodimerize with another ligand-bound member of the EGFR family for activation. Ligand-independent homodimerization will occur in the setting of HER2 overexpression. ${ }^{7}$ Activation leads to autophosphorylation of the intracellular tyrosine kinase domain and downstream signaling of the RAS, MAP, and P13K pathways. HER2 amplification and overexpression plays a central role in disease initiation, progression, and metastasis, and is traditionally associated with a worse prognosis in patients with breast and gastric cancers. ${ }^{8}$

\section{HER2 in gastric cancer}

Amplification of HER2 was described in a gastric cancer cell line initially in $1986 .{ }^{9}$ In 1991 , initial clinical findings were published by Yonemura and colleagues documenting HER2 overexpression to be detected by immunohistochemistry in $11.9 \%$ of 260 Japanese gastric cancer patients. ${ }^{10}$ Many subsequent studies have found amplification or overexpression of HER 2 in $7 \%$ to $34 \%$ of gastric carcinomas. ${ }^{11-16}$ Histologically, HER2 overexpression is more often associated with differentiated tumors ${ }^{17,18}$ as well as intestinal-type tumors ${ }^{11-15,19}$ both of which would imply a more favorable outcome. In the ToGA trial, ${ }^{14}$ which will be discussed later, HER2 overexpression was far more common in intestinal-type (75\%) than diffuse-type (9\%) tumors. The correlation of intestinal-type histology and HER2 overexpression is not well understood but may be partially explained by
E-cadherin mutations. In gastric cancer, HER2 gene amplification associates inversely with E-cadherin mutations ${ }^{20}$ which are more common in diffuse-type gastric and lobular invasive breast carcinomas and rare in intestinal-type gastric and ductal invasive breast carcinomas. ${ }^{13}$ In addition, germline mutations of E-cadherin have been identified that are responsible for a dominantly inherited from of diffuse-type gastric cancer. ${ }^{21}$ However, HER2 overexpression is more often associated with higher T-stage and nodal involvement at time of diagnosis, ${ }^{17}$ which are poor prognostic factors. HER2 overexpressing tumors are most often in the located gastroesophageal junction (33.2\%) rather than the remainder of the stomach $(20.9 \%) .{ }^{14}$

Historically, HER2 overexpression was associated with a significantly worse overall survival. Multiple series confirm these findings. ${ }^{13,15,17,19,22-25}$ However, a recently published European ${ }^{11}$ series as well as two Asian series ${ }^{16,18}$ found that HER2 overexpression does not impact prognosis. Indeed, the patients treated in the chemotherapy alone arm of the ToGA trial ${ }^{14}$ survived to a median of 11.1 months, which is equivalent if not superior to historic comparisons. Therefore, the impact of HER2 overexpression on survival remains unclear, and arguably has little impact.

There has been a concerted effort to standardize HER2 assessment in gastric carcinoma. Compared with breast carcinoma, HER 2 immunoreactivity in gastric carcinoma is more incomplete and heterogeneous. Additionally, HER2 staining results appear to differ by type of specimen, ie, endoscopic biopsy compared with surgically resected specimens. ${ }^{11}$ Hoffman and colleagues ${ }^{12}$ have developed and validated a scoring system for assessing HER2 in gastric carcinomas. Assessment of 168 resection specimens (149 from the stomach and 16 from the gastroesophageal junction) was performed using immunohistochemistry by HecepTest ${ }^{\mathrm{TM}}$ (Dako, Denmark) and fluorescence in-situ hybridization (FISH) by HER2 FISH (pharmDx ${ }^{\mathrm{TM}}$, Dako, Denmark). Twenty-nine samples were considered FISH positive (defined as HER2:CEP17 ratio $\geq 2$ ), while 18 samples were considered positive with IHC $3+$. All 18 samples positive by IHC were positive by FISH, however FISH identified another 11 patients which were considered negative (IHC 0 or $1+$ ) or equivocal (IHC $2+$ ). Discrepancies between IHC and FISH results were attributed to basolateral membranous immunoreactivity of glandular cells resulting in incomplete membranous reactivity along with a higher rate of tumor heterogeneity. Based on the findings of this study, a consensus panel has proposed recommendations on HER2 scoring for gastric cancer (Table 1). 
Table I HER2 immunohistochemical staining classification

\begin{tabular}{lll}
\hline Surgical specimen staining pattern & Biopsy specimen staining pattern & Classification/score \\
\hline $\begin{array}{l}\text { No reactivity or membranous reactivity } \\
\text { in }<10 \% \text { of tumor cells }\end{array}$ & $\begin{array}{l}\text { No reactivity or no membranous reactivity } \\
\text { in any tumor cell }\end{array}$ & Negative/0 \\
$\begin{array}{l}\text { Faint or barely perceptible membranous } \\
\text { reactivity in } \geq 10 \% \text { of tumor cells; cells }\end{array}$ & $\begin{array}{l}\text { Tumor cell cluster with faint or barely perceptible } \\
\text { membranous reactivity irrespective of percentage }\end{array}$ & Negative/I+ \\
are reactive only in part of membrane & of tumor cells stained & \\
Weak to moderate complete, & Tumor cell cluster with a weak to moderate complete, & Equivocal/2+ \\
basolateral or lateral membranous reactivity & basolateral or lateral membranous reactivity irrespective & \\
in $\geq 10 \%$ of tumor cells & of percentage of tumor cells stained & Positive/3+ \\
Strong complete, basolateral or lateral & Tumor cell cluster with a strong complete, basolateral & \\
membranous reactivity in $\geq 10 \%$ of tumor cells & or lateral membranous reactivity irrespective of & \\
\end{tabular}

Copyright $\odot$ 2008. John Wiley and Sons. Adapted with permission from Hofmann M, Stoss O, Shi D, et al. Assessment of a HER2 scoring system for gastric cancer: results from a validation study. Histopathology. 2008;52 (7):797-805. ${ }^{12}$

\section{Clinical trials using trastuzumab}

The results of a study combining trastuzumab with cisplatin in HER2 positive untreated patients with gastric cancer have recently been presented. ${ }^{26}$ Twenty-one patients with advanced gastric or gastroesophageal carcinoma were enrolled. Overall the response rate was reported at 35\% in 17 evaluable patients with final results on survival not available yet. Another study evaluating the role of trastuzumab in the treatment of previously untreated advanced gastric cancer in combination with cisplatin and docetaxel is underway with evidence of preliminary activity. ${ }^{27}$ Our group recently published results of a phase I study evaluating the safety profile of interleukin-12 when given in combination with trastuzumab and paclitaxel to patients with metastatic HER2-overexpressing cancers. ${ }^{28}$ Twenty-one patients were enrolled, four with metastatic gastro-esophageal and two with metastatic gastric adenocarcinomas. The only patients who experienced benefit on this study were those with a diagnosis of breast cancer or gastric/gastro-esophageal cancer. Two of the four patients with metastatic esophageal adenocarcinoma achieved a partial response lasting 25 and 43 weeks, respectively. One of the two patients with gastric cancer maintained stable disease for 62 weeks.

The only randomized controlled study evaluating the activity of trastuzumab in the first-line treatment of HER2 positive advanced gastric and gastroesophageal carcinoma is the recently published Phase III ToGA trial. ${ }^{14}$ This openlabel, randomized controlled trial enrolled patients from 24 countries. In this study, 3807 patients with gastric and gastroesophageal adenocarcinoma were screened for HER2 overexpression, defined as IHC $3+$ or FISH positive (+) as established in the Hoffman trial. ${ }^{12}$ Five hundred and eightyfour patients were randomized to receive cisplatin $80 \mathrm{mg} / \mathrm{m}^{2}$ on 1 day with either 5 -fluorouracil $800 \mathrm{mg} / \mathrm{m}^{2}$ on days $1-5$ or capecitabine $2000 \mathrm{mg} / \mathrm{m}^{2}$ on days $1-14$ alone or in combination with trastuzumab $8 \mathrm{mg} / \mathrm{kg}$ on day 1 followed by $6 \mathrm{mg} / \mathrm{kg}$ administered every 3 weeks until disease progression. The protocol allowed patients who completed six cycles of chemotherapy and trastuzumab to continue on trastuzumab monotherapy until disease progression. The primary end point was overall survival and secondary end points included progression-free survival, time to progression, response rate, duration of response and safety.

Two hundred and ninety-six patients were randomized to the chemotherapy alone arm and 298 patients to the chemotherapy and trastuzumab arm. Median follow-up was 18.6 months in the trastuzumab plus chemotherapy arm and 17.1 months in the chemotherapy alone arm. The study met its primary endpoint with a median overall survival of 13.8 months in the chemotherapy with trastuzumab arm compared with 11.1 months in the chemotherapy alone arm $(P=0.0046)$. All other efficacy parameters were also significantly improved with the addition of trastuzumab to chemotherapy compared with chemotherapy alone (Table 2). It should be noted that the control arm group fared better than historic comparisons. This result may be related to the large proportion of Asian patients enrolled in the study, or more likely the presence of a high rate of intestinal-type histology in the study population. Seventy-seven percent of the experimental group and $74 \%$ of the control group were found to have intestinal-type histology, which is typically associated with better prognosis than diffuse-type histology. Unlike previously published data, ${ }^{11,16,18}$ these findings suggest that tumors overexpressing HER2 may have an equivalent if not favorable prognostic effect.

Therapy was very well tolerated with expected hematologic and gastrointestinal toxicities. The most common side effects were nausea, vomiting, and neutropenia. Patients assigned to trastuzumab plus chemotherapy had slightly higher rates 
Table 2 Results of trastuzumab in combination with chemotherapy vs chemotherapy alone for treatment of HER 2 positive advanced gastric or gastro-esophageal junction cancer (ToGA): a phase 3, open-label, randomized controlled trial

\begin{tabular}{llll}
\hline & Trastuzumab plus chemotherapy & Chemotherapy alone & P value (nonstratified) \\
\hline Overall survival & 13.8 months & 11.1 months & 0.0046 \\
Progression-free survival & 6.7 months & 5.5 months & 0.0002 \\
Time to progression & 7.1 months & 5.6 months & 0.0003 \\
Duration of response & 6.9 months & 4.8 months & $<0.000$ I \\
Overall response rate & $47 \%$ & $35 \%$ & 0.00175 \\
\hline
\end{tabular}

of diarrhea, stomatitis, anemia, thrombocytopenia, fatigue, chills, weight loss, pyrexia, mucositis, and nasopharyngitis. With the exception of diarrhea, rates of grade 3 and 4 adverse events as well as cardiac adverse events were similar between the groups. Eleven patients (5\%) experienced a $\geq 10 \%$ decrease in left ventricular ejection fraction, and up to $<50 \%$ in the trastuzumab and chemotherapy group compared, with two patients $(1 \%)$ in the chemotherapy alone group. The addition of trastuzumab to chemotherapy did not adversely affect quality of life. ${ }^{29}$

\section{Future directions}

The use of trastuzumab in gastric carcinomas is in its infancy and many avenues await exploration. As discussed previously, in advanced gastric carcinoma, trastuzumab has only been studied in combination with cisplatin and 5-FU in the Phase III setting, leading to FDA approval in the United States. However, in advanced HER2-overexpressing breast cancers, trastuzumab is very active in combination with taxanes, a class of chemotherapy active in gastric carcinoma. ${ }^{30-32}$ A pivotal Phase III trial published in 2001 combined trastuzumab with paclitaxel in patients with breast cancer previously treated with anthracyclines. ${ }^{4}$ In comparison to single-agent paclitaxel, the combination of paclitaxel and trastuzumab was associated with a significantly higher response rate of $38 \%$ vs $16 \%$ as well as a 4-month improvement in time to progression. There was also a nonsignificant increase in overall survival from 18 to 22 months. In addition, multiple Phase II studies have suggested superiority of the combination of docetaxel and trastuzumab compared with docetaxel alone. ${ }^{33-35}$ Many consider the combination of a taxane and trastuzumab to represent the best first-line option for women with hormone refractory HER2-overexpressing metastatic breast cancer. In our opinion, similar findings will be found in HER2overexpressing gastric carcinomas, but we cannot endorse the use of trastuzumab with taxanes in the absence of data. Currently, an ongoing Phase II clinical trial is evaluating trastuzumab in combination with docetaxel, cisplatin, and 5-FU (ClinicalTrials.gov number NCT00515411) which may shed some light on this subject. Agents being evaluated in combination with trastuzumab for advanced gastric carcinomas include capecitabine and oxaliplatin, cisplatin and TS-One, and bevacizumab among others.

Resistance to trastuzumab will invariably develop in patients with advanced cancers being treated with trastuzumabcontaining regimens. Indeed, the rate of primary resistance to single-agent trastuzumab in HER2-overexpressing metastatic breast carcinomas is $66 \%-88 \% .^{36-38}$ The conventional wisdom of discontinuing a cytotoxic agent upon progression has yet to be elucidated for novel biologics, and whether trastuzumab treatment should be continued upon progression with a different chemotherapeutic agent has not yet been established. Just as we do not fully understand the mechanisms of action of trastuzumab, we have even less understanding of the mechanisms of resistance. Proposed mechanisms of resistance include activation of multiple downstream signaling pathways such as $\mathrm{P} 13 \mathrm{~K} / \mathrm{AKT}$ pathway which may occur with or without loss of the PTEN tumor suppressor gene, ${ }^{39}$ activation of non-HER2 receptors such as insulin-like growth factor-I, ${ }^{40}$ disruption of the interaction between the therapeutic agent and the target protein through increased expression of membrane-associated glycoprotein (MUC4), ${ }^{41}$ and loss of the binding site on truncated HER2 receptors. ${ }^{42}$ Retrospective studies suggest that trastuzumab administration is indicated after disease progression attributed to an increase in response rate as well as survival. A systematic review revealed that the response rate of second-line therapy along with continuation of trastuzumab was $21 \%$ with a time to progression of 6.7 months which appear promising. ${ }^{43}$ A recently published observational of study of 623 patients found the median time to progression was longer in patients who continued trastuzumab beyond progression (10.2 months) than in those who stopped (7.1 months). ${ }^{44}$ Attempts to answer this question via phase III trials have been unsuccessful, plagued by slow accrual out of reluctance by caregivers and patients to discontinue trastuzumab. SWOG 0347 as well as the German Breast Group 26/Breast International Group $03-05^{45}$ studies were closed early, secondary to poor accrual. In the latter trial, analysis of 
156 of a planned 482 patients revealed a response rate of $27 \%$ and $48 \%$ in patients who stopped and continued trastuzumab, respectively. Trastuzumab use beyond progression was associated with a $31 \%$ reduction of tumor progression and increase in time to progression of 2.5 months. No studies have addressed this question in gastric carcinoma.

Lapatinib (GlaxoSmithKline, Research Triangle Park, NC, USA), an oral small molecule dual tyrosine kinase inhibitor of EGFR and HER2, has been found to be active in HER2-overexpressing cancers. In those with trastuzumabrefractory breast cancer, lapatinib combined with capecitabine had a response rate of $22 \%$ and statistically improved time to progression from 4.4 months in the lapatanib alone group to 8.4 months in the combination arm. ${ }^{46}$ Lapatinib in combination with chemotherapy is being assessed in advanced gastric carcinoma. The Phase III LOGiC trial (NCT00680901) is evaluating the combination of lapatinib in combination with capecitabine and oxaliplatin for firstline HER2-overexpressing gastric carcinomas. The study is actively accruing patients and no efficacy results are available to date. Safety analysis from TYTAN, a Phase III Asian study of lapatinib in combination with paclitaxel as second-line therapy in HER2 overexpressing gastric cancer, revealed no safety issues. ${ }^{47}$ Efficacy results are not yet available.

This review has focused on advanced disease. As seen in breast cancer, trastuzumab is an integral part of adjuvant or neoadjuvant treatment of operable disease. Perioperative chemotherapy using epirubicin, cisplatin, and 5-fluorouracil has been shown to improve survival in operable disease over surgery alone. ${ }^{48}$ A recent Phase III study, RTOG 1010, is evaluating the addition of trastuzumab to trimodality treatment of HER2-overexpressing esophageal adenocarcinoma.

\section{Conclusion}

HER2 overexpression in gastric cancer has been traditionally associated with poor survival, although results from recent studies such as the ToGA trial, appear to contradict this. HER2 targeted therapy with trastuzumab, when combined with chemotherapy (cisplatin and a fluoropyrimidine) has been shown to improve response rate, and progression-free and overall survival compared with chemotherapy alone in patients with advanced gastric or gastroesophageal adenocarcinomas, which overexpress HER2 (IHC 3+ and/or FISH+). In addition to improved outcome, trastuzumab combined with chemotherapy was found to be tolerable with no negative impact on quality of life. As such, trastuzumab should play an integral part in the management of patients with HER2-overexpressing advanced gastric adenocarcinoma. Current studies are evaluating the role of this combined approach in the perioperative setting. Future studies are needed to address the question of how to proceed upon disease progression while on trastuzumab.

\section{Disclosure}

Jeffrey S Rose: None. Tanios S Bekaii-Saab: Consulting fees and grant support from Genentech.

\section{References}

1. National Cancer Institute. Surveillance epidemiology and end results: cancer of the stomach. URL:http://seer.cancer.gov/statfacts/html/stomach.html. Accessed October 2010.

2. Van Cutsem E, Moiseyenko VM, Tjulandin S, et al. Phase III study of docetaxel and cisplatin plus fluorouracil compared with cisplatin and fluorouracil as first-line therapy for advanced gastric cancer: a report of the V325 Study Group. J Clin Oncol. 2006;24(31):4991-4997.

3. Cunningham D, Starling N, Rao S, et al. Capecitabine and oxaliplatin for advanced esophagogastric cancer. $N$ Engl J Med. 2008;358(1):36-46.

4. Slamon DJ, Leyland-Jones B, Shak S, et al. Use of chemotherapy plus a monoclonal antibody against her- 2 for metastatic breast cancer that expresses her-2. N Engl J Med. 2001;344(11):783-792.

5. Gschwind A, Fischer OM, Ullrich A. The discovery of receptor tyrosine kinases: targets for cancer therapy. Nat Rev Cancer. 2004;4(5): 361-370.

6. Baselga J, Swain SM. Novel anticancer targets: revisiting ERBB2 and discovering ERBB3. Nat Rev Cancer. 2009;9(7):463-475.

7. Worthylake R, Opresko LK, Wiley HS. ErbB2 amplification inhibits down-regulation and induces constitutive activation of both ErbB2 and epidermal growth factor receptors. J Biol Chem. 1999;274(13): $8865-8874$.

8. Gravalos C, Jimeno A. HER2 in gastric cancer: a new prognostic factor and a novel therapeutic target. Ann Oncol. 2008;19(9):1523-1529.

9. Yamamoto T, Ikawa S, Akiyama T, et al. Similarity of protein encoded by the human c-erb-B-2 gene to epidermal growth factor receptor. Nature. 1986;319(6050):230-234.

10. Yonemura Y, Ninomiya I, Yamaguchi A, et al. Evaluation of immunoreactivity for erbB-2 protein as a marker of poor short term prognosis in gastric cancer. Cancer Res. 1991;51(3):1034-1038.

11. Grabsh H, Sivakumar S, Gray S, Gabbert HE, Mulller W. HER2 expression in gastric cancer: rare, heterogeneous and of no prognostic value - conclusions from 924 cases of two independent case series. Cell Oncol. 2010;32(1-2):57-65.

12. Hofmann M, Stoss O, Shi D, et al. Assessment of a HER2 scoring system for gastric cancer: results from a validation study. Histopathology. 2008;52(7):797-805.

13. Tanner M, Hollmen M, Junttila TT, et al. Amplification of HER2 in gastric carcinoma: associated with Topoisomerase IIalpha gene amplification, intestinal type, poor prognosis and sensitivity to trastuzumab. Ann Onc. 2005;16(2):273-278.

14. Bang Y, Van Cutsem E, Feyereislova A, et al. Trastuzumab in combination with chemotherapy versus chemotherapy alone for treatment of HER2 positive advanced gastric or gastro-esophageal junction cancer (ToGA): a phase 3, open-label, randomized controlled trial. Lancet. 2010;376(9742):687-697.

15. Zhang XL, Yang YS, Xu DP, et al. Comparative study on overexpression of HER2/neu and HER3 in gastric cancer. World J Surg. 2009;33(10): 2112-2118.

16. Matsubara J, Yamada Y, Hirashima Y, et al. Impact of insulin-like growth factor type 1 receptor, epidermal growth factor receptor, and HER2 expressions on outcomes of patients with gastric cancer. Clin Cancer Res. 2008;14(10):3022-3029.

17. Mizutani T, Onda M, Tokunaga A, Yamanaka N, Sugisaki Y. Relationship of C-erbB-2 protein expression and gene amplication to invasion and metastasis in human gastric cancer. Cancer. 1993:72(7):2083-2088. 
18. Tateishi M, Toda T, Minamisono Y, Nagasaki S. Clinicopathological significance of c-erbB-2 protein expression in human gastric carcinoma. J Surg Onc. 1992;49(4):209-221.

19. Barros-Silva JD, Leitão D, Afonso L, et al. Association of ERBB2 gene status with histopathological parameters and disease specific survival in gastric carcinoma patients. Br J Cancer. 2009;100(3):488-493.

20. Berx G, Becker KF, Hofler H, van Roy F. Mutations of the human E-cadherin (CDH1) gene. Hum Mutat. 1998;12:226-237.

21. Pedrazzani C, Corso G, Marrelli D, Roviello F. E-cadherin and hereditary diffuse gastric cancer. Surgery. 2007;142(5):645-657.

22. García I, Vizoso F, Martín A, et al. Clinical significance of the epidermal growth factor receptor and HER2 receptor in resectable gastric cancer. Ann Surg Onc. 2003;10(3):234-241.

23. Nakajima M, Sawada H, Yamada Y, et al. The prognostic significance of amplification and overexpression of c-met and c-erbB-2 in human gastric carcinomas. Cancer. 1999;85(9):1894-1902.

24. Uchino S, Tsuda H, Maruyama K, et al. Overexpression of c-erbB-2 protein in gastric cancer. Its correlation with long-term survival of patients. Cancer. 1993;72(11):3179-3184.

25. Matsubara J, Yamada Y, Nakajima TE, et al. Clinical significance of insulin-like growth factor type 1 receptor and epidermal growth factor receptor in patients with advanced gastric cancer. Oncology. 2008; 74(1-2):76-83.

26. Cortes-Funes H, Rivera F, Ales I, et al. Phase II of trastuzumab and cisplatin in patients with advanced gastric cancer with HER2/neu overexpression/amplification. In: 2007 ASCO annual meeting proceedings part I. J Clin Oncol. 2007:4613.

27. Nicholas G, Cripps C, Au H-J, et al. Early results of a trial of trastuzumab, cisplatin and docetaxel (TCD) for the treatment of metastatic gastric cancer overexpressing HER2. In: ESMO. Ann Oncol. 2006:Abstract 1105.

28. Bekaii-Saab TS, Roda JM, Guenterberg KD, et al. A phase I trial of paclitaxel and trastuzumab in combination with interleukin-12 in patients with HER2/neu-expressing malignancies. Mol Cancer Ther. 2009;8(11):2983-2991.

29. Satoh T, Leon J, Lopez RI, et al. Quality of life results from a phase III trial of trastuzumab plus chemotherapy in first-line HER2-positive advanced gastric and GE junction cancer. In: 2010 ASCO gastrointestinal cancer symposium, Orlando; 2010.

30. Van Cutsem E, Moiseyenko VM, Tjulandin S, et al. Phase III study of docetaxel and cisplatin plus fluorouracil compared with cisplatin and fluorouracil as first-line therapy for advanced gastric cancer: a report of the V325 Study Group. J Clin Oncol. 2006;24(31):4991-4997.

31. Ajani JA, Moiseyenko VM, Tjulandin S, et al. Clinical benefit with docetaxel plus fluorouracil and cisplatin compared with cisplatin and fluorouracil in a phase III trial of advanced gastric or gastroesophageal cancer adenocarcinoma: the V-325 Study Group. J Clin Oncol. 2007; 25(22):3205-3209.

32. Kornek GV, Raderer M, Scholl B, et al. Effective combination chemotherapy with paclitaxel and cisplatin with or without human granulocyte colony-stimulating factor and/or erythropoietin in patients with advanced gastric cancer. Br J Cancer. 2002;86(12):1858-1863.

33. Esteva FJ, Valero V, Booser D, et al. Phase II study of weekly docetaxel and trastuzumab for patients with HER-2-overexpressing metastatic breast cancer. J Clin Oncol. 2002;20(7):1800-1808.
34. Tedesco KL, Thor AD, Johnson DH, et al. Docetaxel combined with trastuzumab is an active regimen in HER-2 $3+$ overexpressing and fluorescent in situ hybridization-positive metastatic breast cancer: a multi-institutional phase II trial. J Clin Oncol. 2004;22(6):1071-1077.

35. Marty M, Cognetti F, Maraninchi D, et al. Randomized phase II trial of the efficacy and safety of trastuzumab combined with docetaxel in patients with human epidermal growth factor receptor 2-positive metastatic breast cancer administered as first-line treatment: the M77001 study group. J Clin Oncol. 2005;23(19):4265-4274.

36. Baselga J, Tripathy D, Mendelsohn J, et al. Phase II study of weekly intravenous recombinant humanized anti-p185HER2 monoclonal antibody in patients with HER2/neu-overexpressing metastatic breast cancer. J Clin Oncol. 1996;14(3):737-744.

37. Cobleigh MA, Vogel CL, Tripathy D, et al. Multinational study of the efficacy and safety of humanized anti-HER2 monoclonal antibody in women who have HER2-overexpressing metastatic breast cancer that has progressed after chemotherapy for metastatic disease. J Clin Oncol. 1999;17(9):2639-2648.

38. Vogel CL, Cobleigh MA, Tripathy D, et al. Efficacy and safety of trastuzumab as a single agent in first-line treatment of HER2-overexpressing metastatic breast cancer. J Clin Oncol. 2002;20(3):719-726.

39. Lu CH, Wysqomierski SL, Tseng LM, et al. Preclinical testing of clinically applicable strategies of overcoming trastuzumab resistance by PTEN deficiency. Clin Cancer Res. 2007;13(19):5883-5888.

40. Nahata R, Yuan LX, Zhang B, et al. Insulin-like growth factor-I receptor/human epidermal growth factor receptor 2 heterodimerization contributes to trastuzumab resistance of breast cancer cells. Cancer Res. 2005;65(23):11118-111128.

41. Price-Schiavi SA, Jepson S, Li P, et al. Rat MUC4 (sialomucin complex) reduces binding of anti-ErbB2 antibodies to tumor cell surfaces, a potential mechanism of herceptin resistance. Int J Cancer. 2002;99(6): 783-791.

42. Scaltriti M, Rojo F, Ocana A, et al. Expression of p95HER2 receptor and response to anti-HER2 therapies in breast cancer. $J$ Natl Cancer Inst. 2007;99(8):628-638.

43. Fabi A, Metro G, Ferretti G, et al. Do HER2 positive metastatic breast cancer patients benefit from the use of trastuzumab beyond disease progression? A mono-institutional experience and systemic review of observational studies. Breast. 2008;17(5):499-505.

44. Extra J-M, Antoine E-C, Vincent-Salomon A, et al. Efficacy of trastuzumab in routine clinical practice and after progression for metastatic breast cancer patients: the observational Hermine study. Oncologist. 2010;15(8):799-809.

45. Von Minckwitz G, du Bois A, Schmidt M, et al. Trastuzumab beyond progression in human epidermal growth factor receptor 2-positive advanced breast cancer: a German breast group 26/breast international group 03-05 study. J Clin Oncol. 2009;27(12):1999-2006.

46. Geyer CE, Forster J, Lindquist D, et al. Lapatinib plus capecitabine for HER2 positive advanced breast cancer. $N$ Eng J Med. 2006;355(26): 2733-2743.

47. Satoh T, Bang Y, Wang J, et al. Interim safety analysis from TYTAN: a phase III Asian study of lapatinib in combination with paclitaxel as secondline therapy in gastric cancer. J Clin Oncol. 2010;28(15s): Abstract 4057.

48. Cunningham D, Allum WH, Stenning SP, et al. Perioperative chemotherapy versus surgery alone for resectable gastroesophageal cancer. $N$ Eng J Med. 2006;355(1):11-20.
OncoTargets and Therapy

\section{Publish your work in this journal}

OncoTargets and Therapy is an international, peer-reviewed, open access journal focusing on the pathological basis of all cancers, potential targets for therapy and treatment protocols employed to improve the management of cancer patients. The journal also focuses on the impact of management programs and new therapeutic agents and protocols on

Submit your manuscript here: http://www.dovepress.com/oncotargets-and-therapy-journal

\section{Dovepress}

patient perspectives such as quality of life, adherence and satisfaction. The manuscript management system is completely online and includes a very quick and fair peer-review system, which is all easy to use. Visit http://www.dovepress.com/testimonials.php to read real quotes from published authors. 